\title{
Comparative Analysis of Galaxy and Xiaomi on Switching Intention Process of Smartphone Using Structural Equation Modeling
}

\author{
Huifeng Pan $^{1}$ and Man-Su Kang ${ }^{2}$ \\ ${ }^{1}$ Beijing Institute of Graphic Communication; Post-Doctoral Research Station in \\ Business Administration of TsingHua University, Beijing, China \\ $2^{2}$ Department of Research, Korea Federation of Credit Guarantee Foundations, \\ Daejeon 302-847, Korea (Corresponding Author) \\ 1282123934@qq.com, ${ }^{2 *}$ jazzmusi@koreg.or.kr
}

\begin{abstract}
As a result, this study may be considered significant in conducting an in-depth research on the purchasing behavior pattern of the smartphone users in Shanghai, China and in investigating the variables in the effect on the behavior after purchasing Galaxy and Xiaomi among the Chinese smartphone customers. In addition, this study implies that not only the price competitiveness but also technical capabilities should be secured to survive in the smartphone market[1]. The results of this study show that the effect on the channel depends on the brand types of Galaxy and Xiaomi. The results of the analysis are found to show no difference in all channels. As shown in the analysis results of the causal relationship of each channel by dividing Galaxy and Xiaomi into two groups based on all the models in order to prove the detailed difference in two brands towards their customers, the way of dealing with two models respectively shall be different due to the different customer behavior processes of Galaxy and Xiaomi. Accordingly, the marketing strategy to secure the competitive advantage among the competitors in the area of smartphone in China shall be applied differently, which will be helpful to the rise in market share. In addition, the results of this study may be used as the basic data required in establishing the market strategy differentiated from the competitors providing the smartphone in the Chinese smartphone market, which may be the contribution of this study. This study is aim to investigate the switching intention process which is the post purchase behavior of the smartphone users in China targeting the customers in Shanghai, China and to clarify the difference in high-priced Galaxy and middle-low priced Xiaomi targeting the Chinese customers in explaining the behavior after purchasing Galaxy and Xiaomi in terms of perceived value[1].
\end{abstract}

Keywords: Cost-effectiveness, Technical capabilities, Smartphone, Switch intention, Model Comparison, Competitive Strategy

\section{Introduction}

It is common knowledge that smartphone market over the world is dominated by Samsung Galaxy and Apple iPhone. However, Apple iPhone ranks the 5th in the first quarter of 2016 and Samsung Galaxy is pushed out of the top 5 by the Chinese smartphone brands in the Chinese smartphone market share. And while Xiaomi, a Chinese smartphone maker, with $12.8 \%$ of its share in the Chinese market in the first quarter of 2015 topped Apple of $10.2 \%$ and Huawei of $12.3 \%$ by $2.6 \%$ p and $0.5 \%$ p respectively, it ranks the 3rd with $12.2 \%$ followed by Huawei of $15.8 \%$ and OPPO of $12.6 \%$ in the first quarter of 2016. 
With the changes in the Chinese smartphone market on the brink of its warring states period at a violent speed of LTE, the first-generation of the Chinese smartphone makers in China represented by Xiaomi and Huawei led the smartphone market with its costefficiency and the second-generation, including OPPO and Vivo have expanded their influence beyond China as well as in China with their technical capabilities. As mentioned, Chinese smartphone developer HwaWei and XiaoMi are competing with oversea smartphone brands and are outperforming among second generation firms through continuous marketing strategies. However, Xiaomi's market share declined while HwaWei is putting effort to keep the first place in the market share. As if proving such effort, HwaWei's high-end product 'mate 8' created great sensation in the market in Chinese, exceeding four million sales for four months including the first quarter of 2016. Also, HwaWei's mobile shipment has been increased $48 \%$ compared with corresponding period last year. In contrast, global conglomerates like Apple's iPhone, SamSung's Galaxy series are indeed becoming less favorable due to market saturation and price dumping of domestic firms in China. Defeated by Vivo, Apple ranked fifth with imminent decrease in market share nearly under $10 \%$. Situation is worse for Samsung, for which its market share ranked under fifth from long time ago [2].

With continuous decline in market share in China, it is consequential for Samsung and Xiaomi to find causes in order to recover their market share. So what would be the causes for declining market share for Samsung and Xiaomi? Among causal factors such as distribution channel, human resource affair, etc., the most significant factor would be Chinese people's increase in interest for smartphone that has lower-price and bearable performance quality. In other word, it is assumed that firms like OPPO and vivo in which highly advanced technology and cost effectiveness encouraged by Chinese tendency to favor domestic goods along with tacit support by government are available, played major role in chasing existing firms like Xiaomi and Samsung. According to Gartner's [3] presentation, the major factor affecting Chinese when buying mobile is interest in brands and service quality.

The above-mentioned fluctuations in the Chinese smartphone market signify gaining competitive advantage, retaining market share, or marking higher market shares than those of leading companies by immediately managing consumer activity.

Therefore, this research recognized the need for analysis of the range of impact on the aftermath of Chinese customers' smartphone purchases. These researches are necessary since China's smartphone industry's sharp fluctuations indicate the risk of expulsion from market if customer needs are not analyzed and compensated immediately. To test the structural consumer activity results and effects per models, Xiaomi and Galaxy-rivals in Chinese smartphone industry-users in Shanghai, China were tested of relationships between recognized value, customer satisfaction, brand trust, brand loyalty and smartphone transition processing through a specialized research institution on the Internet for the purpose of this research. Individual analysis of the impact of recognized value among Chinese smartphone users in brand trust, customer satisfaction, and brand loyalty on transitions and any differences in variables between Xiaomi and Galaxy will aid in marketing strategies establishment for retaining competitive advantages among Chinese smartphone competitors. Also, when China's smartphone supplying companies request data bases for the establishment of differentiated marketing strategy against rival companies, this research results can be utilized as data bases [1]. 


\section{Theoretical Background}

\subsection{Current Status of the Chinese Smartphone Market}

With the regard to the Chinese smartphone brands, Huawei, Xiaomi, Lenovo, and ZTE, which are growing into the global companies in the recent years are growing in the competitive composition of Samsung Galaxy and Apple iPhone. The Chinese mobile phone market started to take its shape since the establishment of the communication network in Guangzhou City in 1987. In addition, the mobile phones has been imported as the overseas trade since the 1990s and the Chinese mobile phone industry has expanded into the import of the mobile phone, the joint venture, management, and the present research and development of its own since the implementation of the development policy of the mobile communication in 1995.

1.28 billion smartphones were investigated to be opened and used in China in early 2015, which boasts its number of the mobile phones which is the biggest as a single country in the world. As shown in Table 1, Huawei ranks the first in the Chinese market share and all Chinese products except for Apple are in the top five. While Samsung Galaxy had the highest Chinese smartphone market share in 2013 and 2014, since then its market share has continued to decline only to suffer the indignity of being out of the top five in the first quarter of 2016. It is considered difficult for the foreign companies to be successful in the Chinese smartphone market because the domestic companies are preferred and the laws or a variety of regulations are working to the domestic companies' advantage in the Chinese smartphone market. Accordingly, Samsung Galaxy was doomed to be naturally squeezed out by the Chinese consumers who prefer their domestic products as OPPO and VIVO, which are Chinese companies, produced a cheap smartphone whose environment and level were similar to those of Samsung. Only innovative Apple iPhone puts up a good fight in Chinese market with the constructed ecosystem other than that of the other foreign smartphone makers [2].

$<$ Table 1> and <Table 2> show the Chinese smartphone market share, which reveals a good fight of new competitors in the Chinese smartphone market. The frighteningly rapid growth of new competitors in the area of smartphone implies that more efforts shall be made in order to maintain the market share.

Table 1. Top 5 Share and Sales in Chinese Smartphone Market in the First Quarter of 2016 [1]

(Unit: \%, Ten Thousand Devices)

\begin{tabular}{c|c|c|c}
\hline Ranking & Company name & Market share & Sales \\
\hline 1st & Hwawei & 15.8 & 1,657 \\
\hline 2nd & OPPO & 12.6 & 1,322 \\
\hline 3rd & Xiaomi & 12.2 & 1,280 \\
\hline 4th & Vivo & 11.9 & 1,248 \\
\hline 5th & Apple & 11.0 & 1,154 \\
\hline
\end{tabular}




\section{Table 2. Top 5 Share and Changes in their Share in Chinese Smartphone Market in the First Quarter of 2015 and 2016 [1]}

\begin{tabular}{c|c|c|c|c}
\multicolumn{5}{|c}{ (Unit: \%, \%p) } \\
\hline Ranking & Company name & 1Q in 2016 & 1Q in 2015 & Variation \\
\hline 1st & Hwawei & 15.8 & 10.2 & 5.6 \\
\hline 2nd & OPPO & 12.6 & 7.2 & 5.4 \\
\hline 3rd & Xiaomi & 12.2 & 12.8 & -0.6 \\
\hline 4th & Vivo & 11.9 & 7.3 & 4.6 \\
\hline 5th & Apple & 11.0 & 12.3 & -1.3 \\
\hline
\end{tabular}

\subsection{Switching Intention Process}

Switching intention process is composed of factors that motivate and influence actions and an expression of effort to perform certain actions, and the stronger the intention, the more likely the action will be performed [4]. Pan Huifeng and Kang Mansu [5] suggested that the process of switching intent for Chinese smart phone customer should undergo the perceived value, customer satisfaction, brand confidence, brand preference and switching intention[1].

To better understand the switching intention process, one must first understand the perceived value, customer satisfaction, brand confidence and preference [1].

Perceived value needs to be examined from four different perspectives. First of all, value is price. In other words, value can simply be considered as the same notion as price. Secondly, value is what I get for what I give. Thirdly, value is the trade-off between the quality of the goods and the price. The second and the third meaning represent the central role of value in the process of exchange and explains the trade-off between cost and benefit. Lastly, value is a comprehensive assessment of a target of subjective valuation with consideration of assessment criteria [6]. Moreover, value can be explained by an overall assessment of the product and service they received in exchange for the payment and the difference between benefits and costs that result from the use of particular goods or services that offset one another. Such approach to valuation can be defined as the recognition of quality obtained compared to the monetary price (payment) and nonmonetary price (time and effort) when customer compares a product with its competing products, and this approach, based on follow-up research, developed into a strategic perspective $[7-8,1]$.

Customer satisfaction is not only limited to the product, but also extends to the experience of purchase itself, encounter with the salesperson or even with the retail store itself. Customer satisfaction and dissatisfaction are obtained from two dimensions, which are practical utility (how good is the product) and experiential utility (how it feels like to use the product) from a purchase, and can be considered as a positive mood that arises in consideration of aspects of business relationship [9-10].

The approach to customer satisfaction is roughly divided into the one in which customer satisfaction is evaluated by the customer satisfaction of the peculiar trade, which may be considered as the evaluation that customer satisfaction is at least better than expected by the consumption experience with focus on the process and the other in which the customer satisfaction as a cumulative purchase satisfaction is evaluated on the overall cognitive level, which may be the cognitive status of customers that they are properly or improperly compensated by their payment [11].

Customer confidence in the brand is defined as his trust in the capability of the brand through which the needs of the customer are met. In addition, the confidence in the brand may be defined as the customer expectation for the brand that the service providers shall fulfill their promises [12]. Confidence in the brand may be considered as the will of act 
without the immediate calculation of the expenditures and the expected benefits. Customer confidence in the brand is a key factor for building the foundation of the relationship between the company and the customers and the brand equity [13].

With increased social uncertainty, confidence in the brand has emerged as a topic of interest in a variety of fields of business administration, economics, psychology, and politics, which has increased the researches on the confidence due to its multidisciplinary attribute.

Confidence in the area of marketing is considered as important to customers as it has a significant positive effect on a variety of marketing consequences. Brand loyalty is similar to the relationship commitment which the literatures related to relationship marketing in the light that it is expected to maintain the valuable relationship in the concept of brand loyalty and it means its tendency to build a continuous relationship with the commitment to the brand [14-15]. The researches on brand loyalty are divided into the attitudinal loyalty and behavioral loyalty. Close looks at the previous researches in terms of the behavioral loyalty reveal that the behavioral loyalty includes all the cognitive, affective, and intentional elements as the claims of Oliver [16]. Brand loyalty is a concept of brand loyalty or psychological commitment and the behavioral loyalty, which the behavioral loyalty of the customers, may be defined as a repetitive tendency to purchase a particular product, brand, and service within a certain period of time [17].

\subsection{Difference from the Previous Studies}

Unlike the previous studies on only the switching intention process of a single product, or the comparison between the models on the 4 phase - divided process of influence variables as in the study Kang Mansu and Ha Hongyeol (2014) [18], this study is to derive the differences in the path analysis of the switching intention process of Galaxy and Xiaomi. This is expected to provide a useful information for the companies willing to hold a dominant position in competitiveness against the competitors. In other words, it is because a new insight can be found in the gaze at the switching intention process of each smartphone makers through which the competitive strategies may be derived. As the reports of IDC suggest, the evaluation that while Lenovo and Xiaomi which have focused on the smartphones less than 200 dollars based on the cost-effectiveness are stagnant, OPPO and VIVO which well reflect the functions the customers want in the premium smartphone are successful in increasing the net profit rate provides the strategic information necessary on the working-level, which will differentiate the results of this study from those of the other previous studies.

\section{Research Model}

\subsection{Research Model}

In this research, influences of relationship model for smartphone switching intention process of China, which consist of perceived value - customer satisfaction - brand trust brand loyalty - switching intention, on switching intention process of Xiaomi and Galaxy smartphone is examined based on preceding research. Also, mediated effect and difference by product characteristic of Xiaomi and Galaxy - brand type - aroused in the process is hypothesized and examined [1].

By using dimensional reduction, key factors of study model are simplified into 5 factors: perceived value; customer satisfaction; brand trust; brand loyalty; and switching intention. Thus, study model in <Figure 1> is suggested [1]. 


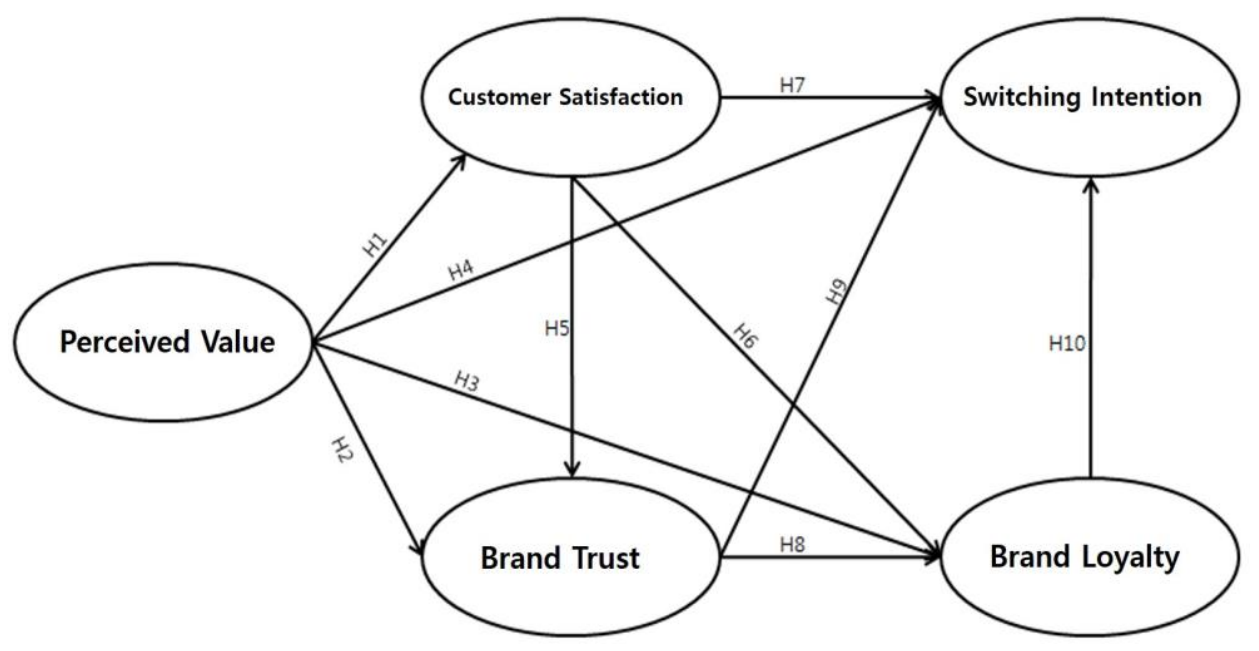

Figure 1. The Research Model [1]

\subsection{Operant Definition and Measurement of Variables}

The list of measurement required in this research is drawn from qualified list of measurement of preceding research. Also, Likert scale (1='Strongly Disagree' $5=$ 'Strongly Agree') is used for each variable in this research, while nominal scale and ordinal scale are used for smartphone brand utilization actuality and questions regarding demographics.

\subsubsection{Perceived Value}

Looking at preceding research about perceived value such as Zeithaml [5] and Bolton \& Drew[7], perceived value is defined as overall evaluation on products and services provided with regard to the price that customers pay. Therefore, perceived value, in this research, is defined as relative perceived value between price paid and benefits offered while using Xiaomi and Samsung services \& products.

Measurement items in this research are modified into 4 items based on measurement list used in preceding research of Zeithaml[6]: 1. Galaxy (or Xiaomi) is valuable in comparison to price paid; 2. Overall benefits of Galaxy (or Xiaomi) are excellent in comparison to price paid; 3. Galaxy (or Xioami) fulfills my shopping needs in comparison to price paid; 4. Galaxy (or Xiaomi) provides enough product information in comparison to price paid.

\subsubsection{Customer Satisfaction}

In preceding research, it is argued that customer satisfaction is a conscious judgment or assessment on whether service is well provided or is appropriate for intended purpose, which can be interpreted through: customer's positive evaluation on extounding consumption experience; or customer's response to difference in perception between expected and actual product performance [11].

Therefore, based on the research of Hunt [11], customer satisfaction in this research can be seen as affective reaction, in other words specific psychology of Chinese customers aroused upon difference between expected and actual smartphone - Galaxy and Xiaomi - product performance, followed by change in customers appetite at specific point.

Measurement items in this research are modified into 2 items based on measurement list used in preceding research of Oliver [16]: 1. Galaxy (or Xiaomi) product is satisfying compared to other brands' product; 2. Purchase of Galaxy (or Xiaomi) is satisfying with experience. 


\subsubsection{Brand Trust}

Credibility in preceding researches means performance and safety of brand products or services. Furthermore, it is defined as customers' assurance on its ability for brand to sustain current functionality and performance. Therefore, in this research, brand trust is defined as trust of Chinese smartphone consumers toward brand upon its quality such as honesty and safety that Galaxy and Xiaomi provide. Measurement items in this research are modified into 3 items based on measurement list used in preceding research of Chaudhuri and Holbrook [19]: 1. Galaxy (or Xiaomi) provides credible smartphone; 2. Galaxy (or Xiaomi) provides smartphone with honesty; 3. Galaxy (or Xiaomi) provides safe smartphone.

\subsubsection{Brand Loyalty}

According to preceding research, preference is defined as immersion in specific brand that allows its products or services continuously favorable. Therefore, in this research, based on the research of Oliver [20], brand loyalty is defined as customers' attitude in which customers who are satisfied with Galaxy and Xiaomi and favor constant purchase through behavioral brand loyalty. Also, Measurement items in this research are modified into 5 items: 1. Would like to recommend Galaxy (or Xiaomi) to others; 2. Will keep purchasing Galaxy (or Xiaomi); 3. Will purchase Galaxy (or Xiaomi) more frequently; 4. I will prioritize Galaxy (or Xiaomi) over other brands; 5. Galaxy (or Xiaomi) is my primary shopping good.

\subsubsection{Switching Intention}

In the research of Bansal and Taylor [21], switching intention is defined as customer's intent to change one brand to another in purchasing products. Therefore, among smartphone users in China, those who use Galaxy and Xiaomi are to be subject to switching intention. In other words, it is assumed that switching intention will be lowered when customer favors brand value formed by Galaxy and Xiaomi. Switching intention is defined as the intent of smartphone users in China to switch from using product of Galaxy and Xiaomi to using that of other brands.

Also, the survey questions are modified based on the preceding research of Bansal and Taylor [21] into 5 measurement items: 1. I will search for the products cheaper than Galaxy (or Xiaomi); 2. I have experience of inquiring about products other than Galaxy (or Xiaomi); 3. Have possibilities for switching to purchase other brand product than Galaxy (or Xiaomi) in the future; 4. I wish to switch to other brands than Galaxy (or Xiaomi); 5. I might be able to purchase brand product other than Galaxy (or Xiaomi) in the future.

\section{Empirical Analysis}

In this research, credibility analysis, principal component analysis, validity analysis, and hypothesis testing are conducted for the empirical analysis, using SPSS 21 and AMOS 21. Key variables are extracted through factorial analysis for dimensional reduction of measurement variables, while validity of the model is verified through exploratory factor analysis. Hypothesis testing is conducted through path-coefficient of structural equating model using AMOS 21. 


\subsection{Exploratory Factor Analysis}

In this research, validity is to be ensured through exploratory factor analysis on perceived value, customer satisfaction, brand trust, brand loyalty, and switching intention. Component matrix of principal component analysis by Varimax rotation is presented in <Table 4>. According to <Table 4>, all factor loadings - perceived value, customer satisfaction, brand trust, brand loyalty, and switching intention - are greater than 0.5 , thus measurement tool showing acceptable validity that reflects property of each factors.

Table 4. Results of Exploratory Factor Analysis

\begin{tabular}{|c|c|c|c|c|c|}
\hline & \multicolumn{5}{|c|}{ Constituents } \\
\hline & 1 & 2 & 3 & 4 & 5 \\
\hline Perceived value1 & -.031 & .206 & .789 & .177 & -.043 \\
\hline Perceived value2 & -.048 & .236 & .586 & -.070 & .329 \\
\hline Perceived value 3 & -.086 & .265 & .658 & .085 & .167 \\
\hline Perceived value4 & .029 & .002 & .701 & .277 & .149 \\
\hline Customer satisfaction 1 & -.051 & .211 & .083 & .170 & .767 \\
\hline Customer satisfaction2 & -.014 & .086 & .284 & .136 & .688 \\
\hline Brand Trust 1 & -.178 & .258 & .309 & .610 & .013 \\
\hline Brand Trust 2 & -.036 & .170 & .091 & .711 & .250 \\
\hline Brand Trust 3 & -.035 & .196 & .108 & .710 & .074 \\
\hline Switching intention 1 & .781 & .060 & -.074 & -.120 & -.023 \\
\hline Switching intention 2 & .767 & -.042 & -.040 & .114 & -.056 \\
\hline Switching intention3 & .824 & -.173 & -.026 & -.061 & .009 \\
\hline Switching intention4 & .811 & -.195 & -.032 & -.115 & -.009 \\
\hline Switching intention5 & .834 & -.147 & .021 & -.088 & -.017 \\
\hline Brand loyalty1 & -.119 & .653 & .119 & .298 & .052 \\
\hline Brand loyalty2 & -.165 & .690 & .214 & .192 & .024 \\
\hline Brand loyalty3 & .068 & .711 & .127 & .003 & .214 \\
\hline Brand loyalty4 & -.170 & .753 & .089 & .100 & .124 \\
\hline Brand loyalty5 & -.140 & .631 & .178 & .216 & .050 \\
\hline
\end{tabular}

Extraction method : Principal Component Analysis. Rotating method: Kaiser VariMax with regularization.

a. 5 Factor rotation is converged in the repetitive calculation

\subsection{Validity Analysis}

In order to assess judgment validity, consistency of the hypothesis proposed by Anderson and Gerbing [22], stating identity between notions (correlation coefficient=1.0), is analyzed. According to their argument, judgment validity is verified when 1.0 are not included in $95 \%$ confidence interval (correlation $\pm 2 \times$ standard error). Therefore, as shown in $\langle$ Table 6$\rangle$ where 1.0 are not included, meaning each factors are not identical, judgment validity of this research is interpreted. 
Table 6. Index Related to Discriminant Validity

\begin{tabular}{l|c|c|c|c}
\hline Objects for Analysis regarding Discriminant Validity & $\begin{array}{l}\text { Estimate of } \\
\text { correlation } \\
\text { coefficient(A) }\end{array}$ & S.E.(B) & A+2×B & A-2×B \\
\hline Perceived value $\leftrightarrow$ Brand confidence & 0.111 & 0.016 & 0.143 & 0.079 \\
\hline Perceived value $\leftrightarrow$ Brand loyalty & .124 & 0.017 & 0.158 & 0.090 \\
\hline Perceived value $\leftrightarrow$ Switching intention & -0.050 & 0.017 & -0.016 & -0.084 \\
\hline Perceived value $\leftrightarrow$ Customer satisfaction & 0.117 & 0.017 & 0.151 & 0.083 \\
\hline Brand trust $\leftrightarrow$ Brand loyalty & 0.136 & 0.018 & 0.172 & 0.100 \\
\hline Brand trust $\leftrightarrow$ Switching intention & -0.089 & 0.019 & -0.051 & -0.127 \\
\hline Customer satisfaction $\leftrightarrow$ Brand trust & 0.100 & 0.016 & 0.132 & 0.068 \\
\hline Brand loyalty $\leftrightarrow$ Switching intention & -0.129 & 0.021 & -0.087 & -0.171 \\
\hline Customer satisfaction $\leftrightarrow$ Brand loyalty & 0.112 & 0.017 & 0.146 & 0.078 \\
\hline Customer satisfaction $\leftrightarrow$ Switching intention & -0.043 & 0.019 & -0.005 & -0.081 \\
\hline
\end{tabular}

\subsection{Measuring Regulation Effect of smartphone Brand Type}

In this research, difference certification method using AMOS 21.0 is conducted to analyze regulation effect hypothesis for each brand type on customers with experience of Galaxy and Xiaomi. 507 Specimens used for analysis are consists of 249 Galaxy users and 258 Xiaomi users.

\subsection{Comparison between Galaxy Group and Xiaomi Group}

This study measured the moderating effects through the brand types and it conducted an analysis on the difference in the path of each group by additionally dividing the basic entire model into Galaxy and Xiaomi in order to identify the difference in the path types of these two brands [1].

As shown in the analysis results of the research model fit (Galaxy), the model is generally satisfied with $\chi^{2} \chi^{2} \chi^{2}=210.287, \mathrm{df}=142, \mathrm{P}=0.000, \mathrm{CFI}=0.959, \mathrm{TLI}=0.948$, $\mathrm{IFI}=0.958$, and RMSEA $=0.044[1]$.

As shown in the test results of the hypotheses, the hypotheses except for H1, H4, H5, $\mathrm{H} 8$ with a significance level higher than $0.1 \%$ were rejected, which had an effect on each path of hypothesis $\mathrm{H} 1, \mathrm{H} 4, \mathrm{H} 5$, and $\mathrm{H} 8$. The hypothesis that each independent variable

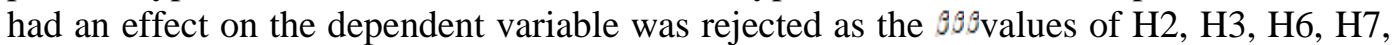
$\mathrm{H} 9, \mathrm{H} 10$ whose hypotheses were rejected were $0.228,0.151,0.345,0.017,-0.584$, and 0.391 respectively and P-value were $0.152,0.226,0.113,0.777$, and 0.159 with a significance level higher than $0.1 \%$ and this hypothesis is accepted as the ${ }^{80} \beta_{\text {values of }} \mathrm{H} 1$, H4, H5, H8 whose hypotheses were accepted were $0.743,0.445,0.473$, and 0.635 respectively and P-value were $0.000,0.086,0.011,0.003$ with a significance level lower than $0.1 \%$. <Table 9> is a result of testing the hypothesis of this study through path analysis using structural equation modeling [1]. 
Table 9. Results of Testing the Hypothesis (Galaxy)

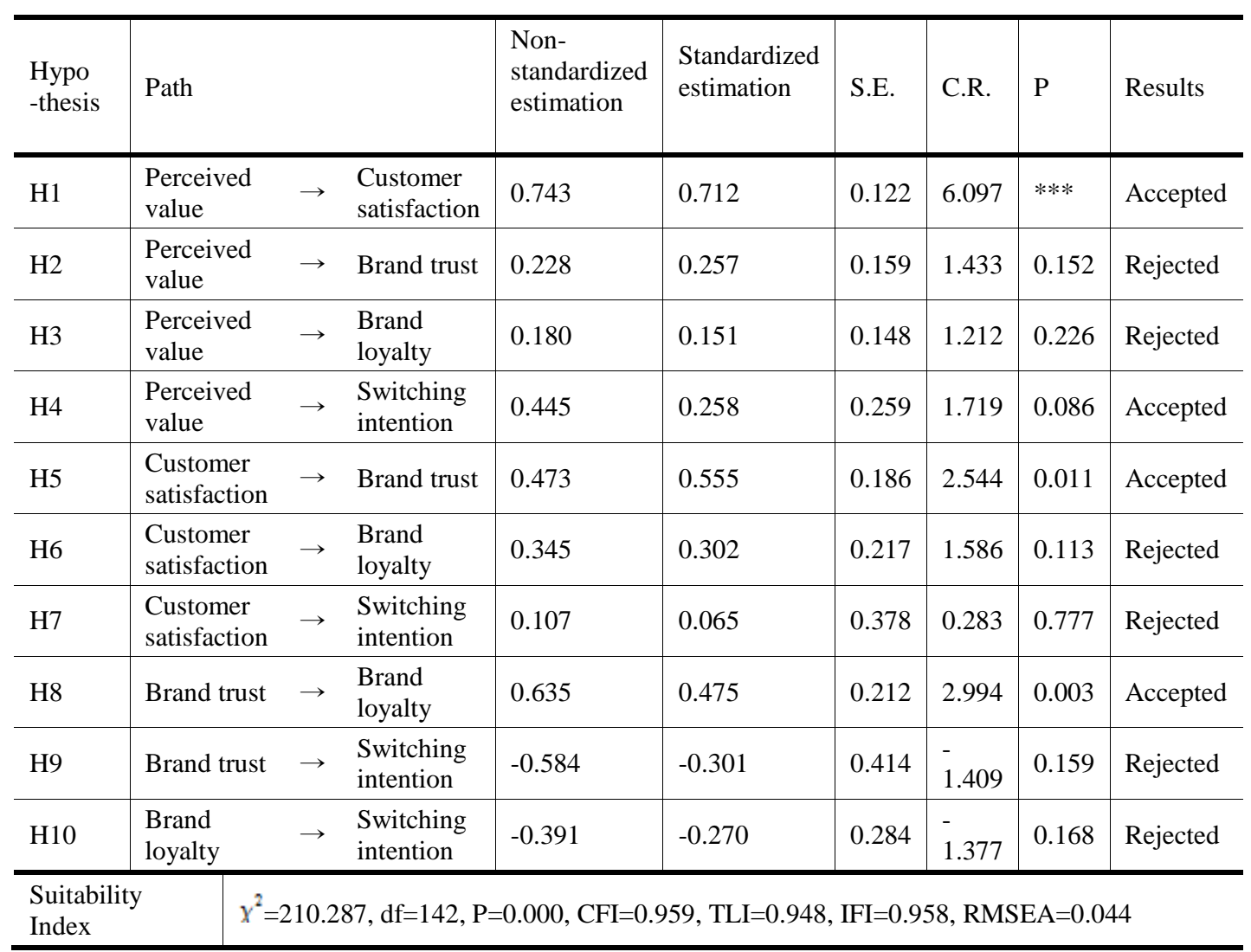

As shown in the analysis results of the research model fit (Xiaomi), the model is generally satisfied with $x^{2}=255.493, \mathrm{df}=142, \mathrm{P}=0.000, \mathrm{CFI}=0.923$, TLI $=0.907, \mathrm{IFI}=0.924$, RMSEA=0.056[1].

As shown in the test results of the hypotheses, the hypotheses except for H1, H2, H5, $\mathrm{H} 8$, and $\mathrm{H} 10$ with a significance level higher than $0.1 \%$ were rejected, which had an effect on each path of hypothesis $\mathrm{H} 1, \mathrm{H} 2, \mathrm{H} 8$, and H10. The hypothesis that each independent variable had an effect on the dependent variable was rejected as the $\theta$ values of $\mathrm{H} 3, \mathrm{H} 4, \mathrm{H} 5, \mathrm{H} 6, \mathrm{H} 7$, and $\mathrm{H} 9$ whose hypotheses were rejected were 0.002, 0.313, 0.070, $0.167,0.999$, and -0.365 respectively and P-value were $0.993,0.399,0.804,0.571,0.999$, and 0.263 with a significance level higher than $0.1 \%$ and this hypothesis is accepted as the ${ }^{\rho}$ values of $\mathrm{H} 1, \mathrm{H} 2, \mathrm{H} 8, \mathrm{H} 10$ whose hypotheses were accepted were $0.569,0.576,0.620$, and 0.669 respectively and P-value were $0.000,0.007,0.000$, and 0.000 with a significance level lower than $0.1 \%$. <Table $10>$ is a result of testing the hypothesis of this study through path analysis using structural equation modeling [1]. 
Table 10. Results of Testing the Hypothesis (Xiaomi)

\begin{tabular}{|c|c|c|c|c|c|c|c|c|c|}
\hline $\begin{array}{l}\text { Hypo } \\
- \\
\text { thesis }\end{array}$ & \multicolumn{3}{|l|}{ Path } & $\begin{array}{l}\text { Non- } \\
\text { standardized } \\
\text { estimation }\end{array}$ & $\begin{array}{l}\text { Standardized } \\
\text { estimation }\end{array}$ & S.E. & C.R. & $\mathrm{P}$ & Results \\
\hline $\mathrm{H} 1$ & $\begin{array}{l}\text { Perceived } \\
\text { value }\end{array}$ & $\rightarrow$ & $\begin{array}{l}\text { Customer } \\
\text { satisfaction }\end{array}$ & 0.569 & 0.774 & 0.125 & 4.554 & $* * *$ & Accepted \\
\hline $\mathrm{H} 2$ & $\begin{array}{l}\text { Perceived } \\
\text { value }\end{array}$ & $\rightarrow$ & Brand trust & 0.576 & 0.676 & 0.212 & 2.716 & 0.007 & Accepted \\
\hline $\mathrm{H} 3$ & $\begin{array}{l}\text { Perceived } \\
\text { value }\end{array}$ & $\rightarrow$ & $\begin{array}{l}\text { Brand } \\
\text { loyalty }\end{array}$ & 0.002 & 0.002 & 0.246 & 0.008 & 0.993 & Rejected \\
\hline $\mathrm{H} 4$ & $\begin{array}{l}\text { Perceived } \\
\text { value }\end{array}$ & $\rightarrow$ & $\begin{array}{l}\text { Switching } \\
\text { intention }\end{array}$ & 0.313 & 0.201 & 0.370 & 0.844 & 0.399 & Rejected \\
\hline H5 & $\begin{array}{l}\text { Customer } \\
\text { satisfaction }\end{array}$ & $\rightarrow$ & Brand trust & 0.070 & 0.061 & 0.283 & 0.249 & 0.804 & Rejected \\
\hline H6 & $\begin{array}{l}\text { Customer } \\
\text { satisfaction }\end{array}$ & $\rightarrow$ & $\begin{array}{l}\text { Brand } \\
\text { loyalty }\end{array}$ & 0.167 & 0.128 & 0.295 & 0.566 & 0.571 & Rejected \\
\hline $\mathrm{H} 7$ & $\begin{array}{l}\text { Customer } \\
\text { satisfaction }\end{array}$ & $\rightarrow$ & $\begin{array}{l}\text { Switching } \\
\text { intention }\end{array}$ & 0.000 & 0.000 & 0.446 & $\begin{array}{c}- \\
0.001\end{array}$ & 0.999 & Rejected \\
\hline $\mathrm{H} 8$ & Brand trust & $\rightarrow$ & $\begin{array}{l}\text { Brand } \\
\text { loyalty }\end{array}$ & 0.620 & 0.550 & 0.209 & 2.968 & $* * *$ & Accepted \\
\hline H9 & Brand trust & $\rightarrow$ & $\begin{array}{l}\text { Switching } \\
\text { intention }\end{array}$ & -0.365 & -0.200 & 0.326 & $\begin{array}{c}- \\
1.119\end{array}$ & 0.263 & Rejected \\
\hline H10 & $\begin{array}{l}\text { Brand } \\
\text { loyalty }\end{array}$ & $\rightarrow$ & $\begin{array}{l}\text { Switching } \\
\text { intention }\end{array}$ & -0.669 & -0.413 & 0.195 & $\begin{array}{c}- \\
3.424\end{array}$ & $* * *$ & Accepted \\
\hline $\begin{array}{l}\text { Suitabi } \\
\text { Index }\end{array}$ & & & & ( & 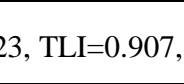 & CI & D & $A=0$ & \\
\hline
\end{tabular}

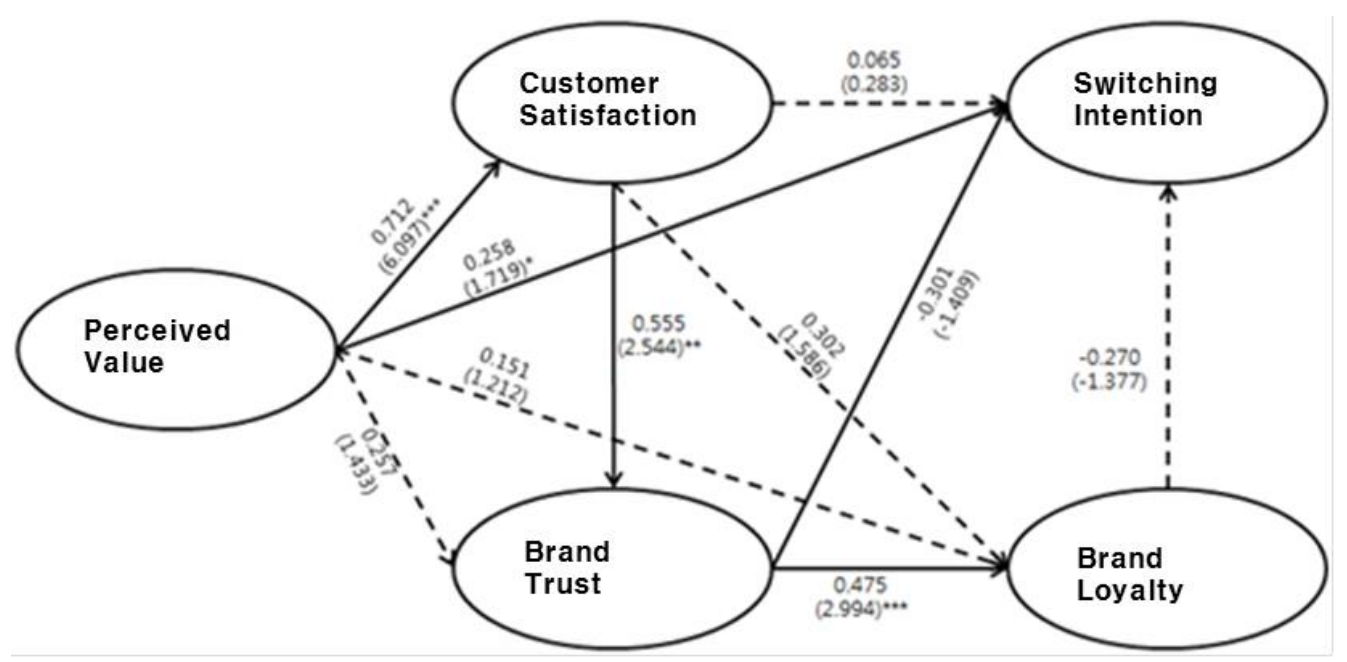

Figure 2. Analysis (Galaxy) 


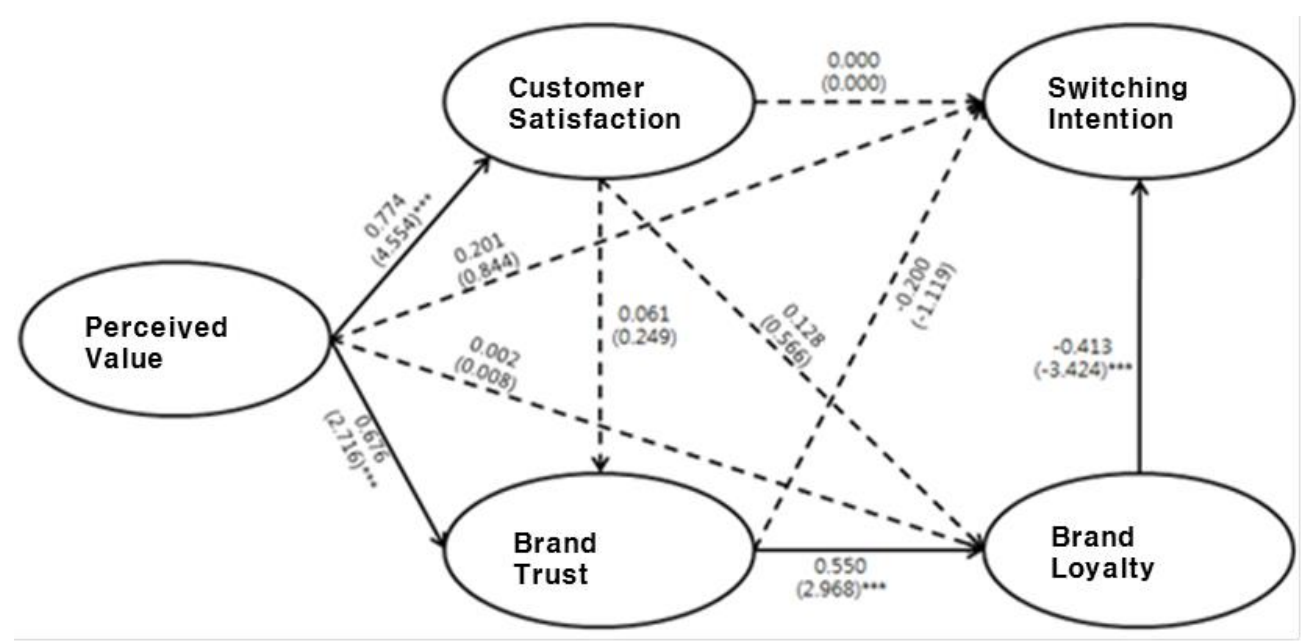

Figure 3. Analysis Results (Xiaomi)

The results of Sobel Test through which mediating effect which happened in each path of the research model (Galaxy) show that customer satisfaction is found to be a parameter of perceived value and brand confidence and in turn brand confidence to be a parameter of customer satisfaction and brand loyalty.

These results suggest that the perceived value forms the process affecting customer satisfaction, brand confidence, and brand loyalty in the Galaxy model.

Table 11. Results of Testing the Mediating Effect (Galaxy)

\begin{tabular}{l|l|l|l|l|l}
\hline Path & Division, & Test statistic & Std. Error & p-value & $\begin{array}{l}\text { Analysis } \\
\text { Results }\end{array}$ \\
\hline \multirow{2}{*}{$\begin{array}{l}\text { Perceived } \\
\text { value }\end{array}$} & Sobel test & 2.34664934 & 0.14976204 & 0.01894307 & Accepted \\
\cline { 2 - 6 }$\rightarrow$ Customer \\
\cline { 2 - 6 } $\begin{array}{l}\text { satisfaction } \\
\rightarrow \text { Brand trust }\end{array}$ & Aroian test & 2.32016679 & 0.15147144 & 0.02033186 & Accepted \\
\cline { 2 - 6 } & $\begin{array}{l}\text { Goodman } \\
\text { test }\end{array}$ & 2.37405991 & 0.14803291 & 0.0175937 & Accepted \\
\hline $\begin{array}{l}\text { Customer } \\
\text { satisfaction } \\
\rightarrow \text { Brand trust } \\
\rightarrow \text { Brand } \\
\text { loyalty }\end{array}$ & Sobel test & 1.93857124 & 0.15493627 & 0.05255357 & Accepted \\
\cline { 2 - 6 } & Aroian test & 1.87868224 & 0.15987536 & 0.06028789 & Accepted \\
\cline { 2 - 7 } & $\begin{array}{l}\text { Goodman } \\
\text { test }\end{array}$ & 2.00457891 & 0.14983446 & 0.04500808 & Accepted \\
\hline
\end{tabular}

The results of Sobel Test through which mediating effect which happened in each path of the research model (Xiaomi) show that brand confidence is found to be a parameter of perceived value and brand loyalty in turn brand loyalty to be a parameter of brand confidence and switching intention.

These results suggest that the perceived value forms the process affecting brand confidence, brand loyalty, and switching intention in the Xiaomi model. 
Table 12. Results of Testing the Mediating Effect (Xiaomi)

\begin{tabular}{|c|c|c|c|c|c|}
\hline Path & Division, & Test statistic & Std. Error & p-value & $\begin{array}{l}\text { Analysis } \\
\text { Results }\end{array}$ \\
\hline \multirow{3}{*}{$\begin{array}{l}\text { Perceived } \\
\text { value } \\
\rightarrow \text { Brand trust } \\
\rightarrow \text { Brand } \\
\text { loyalty }\end{array}$} & & .00361326 & 0.17823799 & 0.0451115 & Accepted \\
\hline & Aroian test & 1.94443422 & 0.18366268 & 0.05184311 & Accepted \\
\hline & Goodma & & & 0.03858863 & Accepted \\
\hline \multirow{3}{*}{$\begin{array}{l}\text { Brand trust } \rightarrow \\
\text { Brand loyalty } \\
\rightarrow \quad \text { Switching } \\
\text { intention }\end{array}$} & Sobel test & -2.24396537 & 0.18484242 & 0.02483463 & Accepted \\
\hline & Aroian test & -2.19133306 & 0.18928204 & 0.0284277 & Accepted \\
\hline & Goodman test & -2.3005819 & 0.18029352 & 0.02141528 & Accepted \\
\hline
\end{tabular}

\section{Conclusions}

\subsection{Result Summary and Implication}

The purpose of this research was to examine how each component of switching intention process (perceived value, customer satisfaction, brand trust, and brand loyalty), which targets smartphone users in China, specifically thosei n Shanghai where Galaxy and Xiaomi were major service providers, is linked to switching intention. Influence of switching intention processes on the behavior of customer who purchased Galaxy and Xiaomi is also examined, while regulation effect, mediated effect, and differences between measured variables in each smartphone switching intention process are identified. In order to achieve this goal, questionnaires for measuring perceived value, customer satisfaction, brand trust, brand loyalty, and switching intention is made based on preceding researches. Empirical analysis is executed on collected data using statistical program SPSS 21 and AMOS21. In empirical analysis, hypotheses drawn from study model are proved.

\subsubsection{Research Result}

First, perceived value has been well studied in marketing field. However, in most research, perceived value is explaining causal relationship between credibility, satisfaction, brand loyalty, and switching intention, while study on comparing and elaborating causal relationship of each brand and that of switching intention, credibility, satisfaction, brand loyalty of clients in China. Also, comparative study on smartphone brands in Korea and China is scarce. Thus, this research aimed at investigating action of customers in Shanghai after purchase, and identifying difference between high-priced Galaxy and lower-priced Xiaomi in level of perceived value for Chinese customers. In addition, subjects researched are selected upon not only their ability to purchase, but also people aged 20s to 30s, in which the most interest in smartphone is expected. As a result, this research represents much in studying both profound behavior patterns of purchasing for smartphone customers in Shanghai and effect of purchasing Galaxy or Xiaomi smartphone on one as smartphone user in China.

Regulation effect of selected channel for each brand type using Galaxy and Xiaomi is analyzed for the research result. Even though analyzed result showed no difference in every channel, in order to verify detailed differences of each brand's customer, causal relationship analysis on course model with two separate group (Galaxy and Xiaomi) based on the whole model. As the result suggests, failure in regulation effect measurement due to distinct customer behavior process of Galaxy and Xiaomi should be noted.

Looking at analytic result of two groups, for group of Chinese customer using Galaxy, it is suggested that the process in which perceived value directly influences customer 
satisfaction and switching intention, brand trust influenced by customer satisfaction, and customer satisfaction influences brand loyalty through brand trust. For Galaxy users, influence factor for switching intention is not formed through certain process, instead, perceived value directly influence switching intention - higher the perceived value, higher switching intention. In case of using high-price Galaxy smartphone, user with high perceived value tends to have increased switching intention when reasonable value is given back [1].

For Chinese customers using Xiaomi showed customer satisfaction and brand trust are influenced directly by perceived value, but it is shown that perceived value has zero mediated effect on brand trust and brand loyalty through customer satisfaction. For Xiaomi with lower-price strategy, perceived value does not directly influence switching intention, but it does through brand trust and brand loyalty, thereby requiring continuous process management [1].

\subsubsection{Implication}

First, contrary to expectation, rising domestic firms in China are invading market product with both competitive price and advanced technology, instead of focusing on increase in market share with low-price products, eventually threatening large firms like Samsung and Apple. As interest in smartphone market in China grows rapidly, in order to increase market share in response to increased demand, appropriate marketing strategy upon perceived value in compulsory. In other words, only those firms respond to rapidly changing market will survive.

Second, as smartphone supplier, global firms in China including Xiaomi should be aware of links connected and causal relationship of perceived value, customer satisfaction, brand trust, preference, switching intention. Especially firms like Apple and HwaWei should have better understanding on behavior pattern of purchase for Galaxy and Xiaomi. For example, the reason for fall of Galaxy and Xiaomi in China market may include issue with distribution channel and price competitiveness, but the most important factor is that not only the interest of customers in China in smartphone is increased, but also China's culture to favor domestic product made foreign firms harder to enter the market compared to Chinese ones.

Third, in Galaxy's consumer behavior process, causal relationship of perceived value$>$ customer satisfaction->brand trust- >brand loyalty in order, and decreasing switching intention as perceived value increases suggests its need for Samsung to draw smartphone customer's attention on high-price premium strategy. This kind of strategy is can challenge preference on domestic product. However, Xiaomi is in trouble as product become high-quality while maintaining low price. As a result, Galaxy's 2015 market share in China market is declining.

Fourth, customer behavior process of Xiaomi are connect under causal relationship: perceived value->brand trust->brand loyaty->switching intention. Enhancing its value, and securing brand trust followed by rise in brand loyalty can prevent customer switching from Xiaomi. Xiaomi should use strategy to utilization of culture favoring domestic products and customer savior process. In other words, online store strategies - which is considered the biggest strength, - should be doubted as factor for market share decline. Because, online contraction of smartphone supply happens more rapidly than off-line contraction does. This is because HwaWei and Oppo minimized damage by maintaining balance between off-line online supply of smartphone, whereas Xiaomi focused on online distribution, suffering from rapid decrease in sales volume.

At last, new competitors in China smartphone market are rising tension among existing smartphone firms. Oppo and Vivo, who had insignificant market share in China market between 2013 and 2015, are now ranked as 2nd and 4th, respectively, with more than $10 \%$ market share. Lots of effort should be made to keep market share from rapidly growing smartphone competitors. Likewise, when existing service providers request 
fundamental data is for establishing marketing strategy, it is implied that theories in this research can be used.

\subsection{Limitation and the Direction for Future Study}

First, this research is based on survey from selected group of people who purchased Galaxy and Xiaomi, and are official classes from the firm in Shanghai, aged 20s to 30s. As a result, generalization of research result is limited. In future research, it should be conducted in various city like Beijing or Hong Kong, and with diversity of classes.

Second, focus on only Galaxy and Xiaomi rather than on iPhone, Huawei, Oppo, Vivo, etc., which can be limitation. It is considered as required procedure for expanded result for whole China smartphone market

Third, questionnaire is collected online. It was through Chinese professional research institute, which assure reliability, research process cannot be managed by researcher. Research through professional researcher to guarantee credibility of surveyor's response

Fourth, in overall switching intention, perceived value only considered monetary aspect, not only ignoring temporal and societal values, but also word-of-mouth effect or immersion is not understood. Research with more varied variable will be required.

\section{References}

[1] H. F. Pan and M. S. Kang, "A Study on the Switching Intention Process of Smartphone”, Asia-pacific Proceedings of Applied Science and Engineering for Better Human Life, vol. 3, (2016), pp. 13-16.

[2] "Financial News", http://www.fnnews.com/news/201604291708037969, (2016).

[3] "Gartner", http://www.gartner.com/newsroom/id/2996817, (2015).

[4] A. Icek, "The theory of Planned Behavior", Organizational Behavior and Human Decision Processes, vol. 50, (1991), pp. 179-211.

[5] H. F, Pan and M. S., Kang, "A Study on the Effects of the Perceived Value about Smart Phone's Customer Behavior: Focusing on Switching Intention", Advanced Letter, (2016), pp.28-32.

[6] A. Z. Valarie, "Consumer Perceptions of Price, Quality, and Value: A Means-End Model and Synthesis of Evidence", Journal of Marketing, vol. 52, no. 3, (1988), pp. 2-22.

[7] R. N. Bolton and J. H. Drew, "A Longitudinal Analysis of the Impact of Service Changes on Customer Attitude", Journal of Marketing Research, vol. 55, no. 1, (1991), pp. 1-9.

[8] R. Blackwell, P. Miniard and J. Engel, "Consumer Behavior (9th eds)", New Youk: Harcourt, (2001).

[9] L. O. Richard, "Cognitive, Affective and Affective Base of Satisfaction Response", Journal of Consumer Research, vol. 20, no. 3, (1993), pp. 418-430.

[10] I. Geyskens, J. B. E. M. Steenkamp and N. Kumar, "A meta-Analysis of Satisfaction in Marketing Channel Relationship", Journal of Marketing Research, vol. 36, no. 1, (1999), pp. 223-238.

[11] H. K. Hunt, "Conceptualization and Measurement of Consumer Satisfaction and Dissatisfaction", Marketing Science Institute, (1977), pp. 77-103.

[12] Hess, "Construction and Assessment of a scale to Measure Consumer Trust", Journal of American Marketing Association, Chicago, IL, Summer, vol. 6, (1995), pp. 20-26.

[13] J. O’Shaughnessy, "Explaining Buyer Behavior”, New York: Oxford University Press, (1992).

[14] C. Moorman, R. Deshpande and Zaltman, "Factors Affecting Trust in Market Research Relationships", Journal of Marketing, vol. 57, no. 1, (1993), pp. 81-101.

[15] R. M. Morgan, and S. D. Hunt, "The Commitment-Trust Theory of Relationship Marketing", Journal of Marketing, vol. 58, no. 3, (1994), pp. 20-38.

[16] L. O. Richard, "Satisfaction: A Behavioral Perspective on the Consumer", New York: McGraw-Hill. Co, (1997).

[17] C. Flavian, E. Martinez and Y. Polo, "Loyalty to Grocery Stores in the Spanish Market of the 1990s", Journal of Retailing and Consumer Services, vol. 8, no. 2, (2001), pp. 85-93.

[18] A. Chaudhuri and M. B. Holbrook, "The chain of effects from brand trust and brand affect to brand performance: The role of brand loyalty", Journal of Marketing, vol. 65, (2001), pp. 81-93.

[19] L. O. Richard, "Whence Consumer Loyalty?", Journal of Marketing, vol. 63, (1999), pp. 33-44.

[20] H. S. Bansal and S. F. Taylor, "The Service Provider Switching Model(SPSM) a Model of Consumer Switching Behavior in the Services Industry", Journal of Service Research, vol. 2, (1999), pp. 200-218.

[21] C. A. Jarnes and W. G. David, "Structural Equation Modeling in Practice: A Review and Recommended Two-Step Approach”, Psychological Bulletin, vol. 50, no. 2, (1988), pp. 179-211. 


\section{Authors}

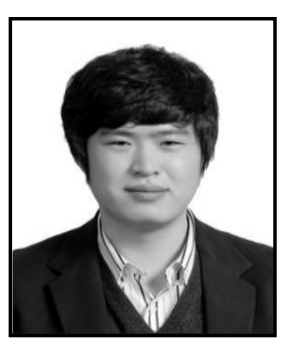

Huifeng Pan, PhD, works currently as in Beijing Institute of Graphic Communication; Post-Doctoral Research Station in Business Administration of Tsing Hua University, Beijing, China. His research interests are culture marketing, consumer behavior, IT services and communication services.

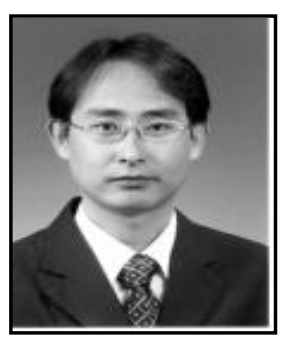

Man-su Kang, $\mathrm{PhD}$, works currently as a senior researcher in the Korea Federation of Credit Guarantee Foundations, Republic of Korea. His research interests are related broadly to big-data analysis from small data analysis, and Finance Service Marketing. 